\title{
DE QUITO A ESPAÑA: ENVÍOS DE OBRAS DE ARTE DURANTE EL BARROCO
}

\author{
FROM QUITO TO SPAIN: SHIPMENTS \\ OF ARTWORKS DURING THE \\ BAROQUE PERIOD
}

\author{
Ángel Justo Estebaranz \\ Universidad de Sevilla, España \\ ajestebaranz@us.es
}

En este artículo se aborda el tema de los envíos de piezas artísticas desde Quito hasta la Península entre la segunda mitad del siglo XVII y comienzos del XVIII. A través de documentación inédita procedente de archivos ecuatorianos y españoles, se analizan remesas desconocidas a diferentes poblaciones de España, el trayecto de las piezas, los custodios de los envíos, los costes de éstos y la distribución de las piezas en cajas y fardos.

Palabras clave: Envíos de obras de arte, Quito, España, barroco, travesía

In this paper, the shipments of artistic pieces from Quito to the Peninsula between the second half of the XVII century and the begining of the XVIII is addressed. Through unpublished documents from Ecuadorian and Spanish archives, unknown shipments to different villages of Spain, the path of the work, the custodians and the costs of shipments, and the distribution of parts in boxes and packages are analyzed.

Keywords: Shipments of artworks, Quito, Spain, baroque, journey

El envío de piezas de América a España durante la Edad Moderna es un tema que ha suscitado un notable interés para la investigación. Su estudio permite ver el flujo de obras de arte hacia la Metrópolis, qué tipo de piezas interesaban más -ya fuera por sus cualidades formales, su valor económico o su rareza-, quién enviaba las obras, hacia dónde, por qué y con qué finalidad, y cómo eran recibidas estas piezas en la Península, entre otras cuestiones. Algunos autores se han 
centrado en los envíos de cierto tipo de piezas $^{1}$, mientras que otros han indagado en los legados de obra americana a determinadas localidades, interesándose por el periplo de las mismas hasta su destino ${ }^{2}$.

En Quito existen algunos casos bien conocidos de piezas artísticas enviadas a la Metrópoli. Quizás el ejemplo más sobresaliente y mejor estudiado sea la pintura de Los Mulatos de Esmeraldas, realizada por el pintor indio Andrés Sánchez Gallque en 1599, abordada en múltiples ocasiones y de la que se conocen las circunstancias de ejecución, envío y destino ${ }^{3}$. Asimismo, se ha investigado sobre las verdaderas intenciones del comitente de la pintura, el oidor Juan del Barrio Sepúlveda, quien pretendía con esta obra poner de relieve su labor como funcionario ante la Corona. Junto a esta pintura, las láminas de la Flora de Bogotá o las de la Flora de Guayaquil, ambas con participación de pintores quiteños, también son conocidas 4 . Pero muchos otros envíos a la Península de obras artísticas realizadas en Quito no se habían estudiado, bien por no conservarse actualmente las piezas, bien por estar actualmente dispersas o no identificadas, bien por falta de investigación en archivos. A pesar de ello, lo cierto es que muchos peninsulares emigrados a Quito, como lo hicieran también los residentes en otros territorios de Ultramar, decidieron enviar obras de arte y cantidades de dinero a sus lugares de origen cuando hicieron fortuna. Gran parte de estos envíos, como reconoce Paniagua, aparecían recogidos en las mandas testamentarias, donde se consignaban las piezas o el dinero destinado a la Península ${ }^{5}$. También se remitían piezas a las autoridades de la Metrópoli, para que éstas tuviesen entre sus posesiones algunas de las más genuinas creaciones de estos territorios o para que tuvieran conocimiento

${ }^{1}$ MANTILLA R., Luis Carlos: "El envío de preciosidades de América a España en el siglo XVIII", Revista de la Academia Colombiana de Ciencias Exactas, Físicas y Naturales, Vol. XXII, 82, 1998, pp. 101-107.

2 PALOMERO PÁRAMO, Jesús Miguel: Plata labrada de Indias. Los legados americanos a las iglesias de Huelva. Patronato Quinto Centenario, Huelva, 1992.

${ }^{3}$ Entre otros, GUERRA, Manuel Patricio: "Una pintura, un memorial, una historia... Los tres mulatos de Sánchez Gallque". En Arte quiteño más allá de Quito. FONSAL, Quito, 2010, pp. 339-355; GUTIÉRREZ USILLOS, Andrés: "Nuevas aportaciones en torno al lienzo titulado "Los mulatos de Esmeraldas". Estudio técnico, radiográfico e histórico", Anales del Museo de América, 20, 2012, pp. 7-64, y WEBSTER, Susan Verdi: "El arte letrado: Andrés Sánchez Gallque y los pintores de principios de la época colonial", en Andrés Sánchez Gallque y los primeros pintores en la Audiencia de Quito. Casa de la Culturas Ecuatoriana, Quito, 2014, pp. 25-97.

${ }^{4}$ Junto a estas piezas cabría destacar otras, como los seis lienzos representando a tipos de la Real Audiencia de Quito, obra de Vicente Albán (1783) que formaron parte de las colecciones del Museo de Ciencias Naturales de Madrid, y cuyos motivos de encargo y llegada a territorio español se conocían, al menos parcialmente.

5 PANIAGUA PÉREZ, Jesús: "Arte quiteño en algunos lugares de España", en Arte quiteño más allá de Quito. FONSAL, Quito, 2010, p. 313. 
de nuevos santos o beatos americanos ${ }^{6}$. Nosotros tratamos en este artículo acerca de algunas remesas desde tierras quiteñas a la Metrópoli entre la segunda mitad del siglo XVII y los primeros lustros del XVIII, aportando documentación procedente de archivos quiteños y españoles.

\section{LAS PIEZAS ENVIADAS Y LOS MOTIVOS}

Las obras que partían de tierras americanas hacia la Península podían ser enviadas por diversas razones. El comitente de Los Mulatos de Esmeraldas pretendía el futuro reconocimiento de una ardua labor, que estaría respaldada con el bautizo de los caciques de la problemática región bajo su mandato. Otros envíos carecían de intención política, y se realizaban como agradecimiento por haber prosperado en estos territorios. Los afortunados indianos agasajaban a familiares y amigos que habían quedado en su tierra natal con piezas de platería y ajuar doméstico, pinturas, esculturas y diferentes cantidades de dinero. En el Barroco cabe destacar a dos obispos de Quito, Alonso de la Peña Montenegro y Diego Ladrón de Guevara, cuyos envíos atendían a las dos posibilidades, pues ambos legaron importantes piezas artísticas y notables cantidades de dinero a familiares y allegados, así como también obras destinadas a ornar iglesias ya existentes -con las que tenían una especial vinculación merced a su procedencia-, u otras de nueva construcción, como es el caso de la capilla de San Ildefonso de Padrón, empeño especial del obispo De la Peña Montenegro para con su villa natal ${ }^{7}$. También es

${ }^{6}$ Es el caso del envío en 1795 de un "Retrato o Imagen" de la entonces Venerable Mariana de Jesús a la Reina de España, devota de esta religiosa quiteña, y que guardaría un parecido con el retrato que había realizado en el siglo anterior el jesuita Hernando de la Cruz, pintor y confesor de la religiosa. Véase la carta que escribió José García de León y Pizarro, quien había sido Presidente de la Real Audiencia de Quito, al Duque de la Alcudia. Archivo General de Indias (AGI), ESTADO,72,N.11, s.f.

Como ejemplo del envío de obra original quiteña a la Península cabe destacar las remesas de cajones de piezas de loza fina realizadas en la Fábrica activa en Quito entre 1771 y 1788, la primera de ellas destinada al presidente de la Casa de la Contratación de Cádiz y la segunda al rey. Véase PANIAGUA PÉREZ, Jesús: "Un intento de reactivación económica en el Quito del siglo XVIII. La fábrica de loza fina", Estudios de historia social y económica de América, 12, 1995, pp. 102-103. A ésta añadía Paniagua otras realizadas en el siglo XVII, que citaba brevemente. Véase PANIAGUA PÉREZ, Jesús: "Arte quiteño en algunos lugares de España”..., op. cit., p. 314.

7 Véase JUSTO ESTEBARANZ, Ángel: "Don Alonso de la Peña Montenegro, obispo de Quito, y algunas de sus fundaciones en Galicia", Compostellanum, 52, no 3-4, 2007, pp. 633-650. También podemos citar aquí el Monasterio de la Concepción de Segura (Guipúzcoa) y el Seminario de San Mateo de Valderas (León), ambos construidos con dinero procedente de los territorios de la Real Audiencia de Quito. Véase PANIAGUA PÉREZ, Jesús: “Arte quiteño en algunos lugares de España”..., op. cit., pp. 314-316. En 
en este caso el reconocimiento de una deuda con la tierra de nacimiento lo que hace plantearse a ambos prelados un importante desembolso en forma de piezas -de platería, sobre todo-y dinero en efectivo. Pero no todo indiano establecido en Quito podía permitirse remitir a su tierra natal, como había hecho el obispo gallego Alonso de la Peña Montenegro en 1659, más de 62.000 pesos y varias piezas de platería o, ya en 1662, 77.000 pesos de a ocho reales y una cantidad pasmosa de piezas de platería, destinadas a diversas iglesias de Galicia, entre ellas la Colegiata de Iria Flavia y la Catedral de Santiago de Compostela ${ }^{8}$. Otros menos pudientes agradecieron su buena posición en la medida de sus posibilidades. Un caso interesante es el envío que hacía a fines del siglo XVII Bartolomé Zuleta de Reales, capitán de origen sevillano establecido en Quito. El destino de su donación fue la iglesia del convento de monjas dominicas de la Pasión de Sevilla porque su padre, Diego Zuleta de Reales, y otros antepasados, habían sido enterrados allí. Al no haber podido contribuir con alguna donación en años anteriores, tenía ahora la oportunidad de cumplir sus deseos, como atestiguaba en el documento notarial redactado en Quito en septiembre de $1696^{10}$. La lámpara de plata enviada a la ciudad hispalense, que pesaba 150 marcos y 5 onzas, estaba destinada a alumbrar día y noche al Santísimo Sacramento ${ }^{11}$. Aunque en otras ocasiones se remitían ciertas cantidades de dinero para que estas piezas se labrasen en la Península, fueron varias las ocasiones en que se enviaron las lámparas ya trabajadas por plateros en América ${ }^{12}$.

relación al obispo Ladrón de Guevara, véase JUSTO ESTEBARANZ, Ángel: "Las donaciones a España del obispo de Quito don Diego Ladrón de Guevara", Artigrama, 24, 2009, pp. 225-237.

8 JUSTO ESTEBARANZ, Ángel: "Don Alonso de la Peña Montenegro...”, op. cit., pp. 636-643.

${ }^{9}$ Archivo Nacional de Historia del Ecuador (ANH), Sección Protocolos Notariales,

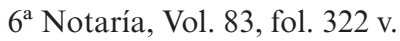

${ }^{10} \mathrm{Su}$ modo de obrar es diferente al de otros peninsulares establecidos en Quito con interés en dotar con nuevas piezas quiteñas a la iglesia de su villa natal. Por ejemplo, Domingo Díaz de Anna, natural de Vitoria, y según manda testamentaria de 1696, mandaba 1.000 pesos para que se labrara una lámpara de plata a Nuestra Señora del Rosario del Convento de Santo Domingo de esta ciudad. Véase ANH, Sección Protocolos Notariales,

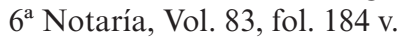

${ }^{11}$ Con 500 pesos enviados, que habrían de imponerse a censo, se pagaría el aceite necesario para mantenerla encendida.

${ }^{12}$ Palomero dedicaba un texto a los legados de plata procedente de las Indias a las iglesias de Huelva. En él aludía al traslado de los envíos desde su lugar de procedencia. Entre las piezas enviadas a la población de origen del personaje figuran algunas destinadas al ornato de las iglesias. Y además, no es raro encontrar piezas de la misma tipología en los envíos a una u otra iglesia. Por ejemplo, el capitán D. García Fernández Caballero, oriundo de Valverde del Camino y residente en Cajamarca la Grande, donde era Gobernador, enviaba a la ermita de Nuestra Señora la Coronada, de Calañas, una lámpara de 
Otros envíos desconocidos hasta ahora son el de Pedro Martínez González, natural de San Miguel de La Palma (Canarias), quien había ordenado que se mandase una importante cantidad de obras a su isla natal en febrero de $1677^{13}$. A diferencia de Zuleta de Reales, en este envío eran múltiples y variadas las piezas de platería, escultura y pintura que se remitían, perfectamente detalladas en la documentación notarial quiteña. Como este personaje había fallecido el año anterior, era su albacea testamentario y heredero, el padre dominico fray Francisco Fernández, quien se encargaba de las gestiones. Entre las piezas que citaba aparecían muchas de platería - tanto para el ajuar litúrgico como para el servicio doméstico-, más algunas imágenes realizadas en naranjo, varias láminas, un cajón de madera forrado en cuero que contenía tres lámparas de plata con sus cadenas, remates y tornillos, arandelas y demás adherentes en 32 envoltorios de papel, dos cruces de madera, etc. Todas estas piezas se disponían en un cajón. En otro cajón de madera con candado pequeño iban otras tantas piezas de platería destinadas al uso litúrgico ${ }^{14}$.

Diversas remesas desde Quito a España, realizadas en esta época, nos pueden ayudar a ampliar el espectro de piezas enviadas y el modo y lugar de su factura. Aunque a veces se mandaba dinero para que se labrasen las piezas en tierras peninsulares, interesa citar aquí las que se habían realizado previamente, o bien las que se ordenaba realizar antes del envío. En primer lugar podemos mencionar la que hace Juan de Ávila, natural de Bienvenida (Extremadura) y residente en Quito, quien donaba en diciembre de 1695 por manda testamentaria varias piezas a Moguer. Concretamente señalaba que, de la plata labrada que poseía,

plata. La pieza, que estaba en 1636 en el santuario del Andévalo (uno de los que atraía a más devotos), pesaba 13 marcos y 2 onzas. Véase PALOMERO PÁRAMO, Jesús Miguel: Plata labrada de Indias. Los legados americanos a las iglesias de Huelva. Patronato Quinto Centenario, Huelva, 1992, p. 47.

${ }^{13}$ ANH, Sección Protocolos Notariales, $1^{\text {a }}$ Notaría, Vol. 242, fol. 346 v-349 v. No fue éste el único envío de piezas al Santuario desde América. Por ejemplo, Domingo Hernández, vecino de La Habana, había regalado a la imagen unas joyas, entre las que destacaba una cruz de esmeraldas, oro y esmaltes. Véase FERNÁNDEZ GARCÍA, Alberto-José: Real Santuario Insular de Nuestra Señora de las Nieves. Editorial Everest, S.A., León, 1980, p. 42.

${ }^{14}$ Las piezas mencionadas eran tres viriles de plata dorada con toda su armazón en 18 envoltorios, otra lámpara de plata con su remate, en 7 envoltorios, 5 hechuras de imágenes de naranjo y una de ellas de piedra, dos crucifijos, una lámina de Cristo guarnecida de plata en su cajón, una calavera en lienzo, dos cruces de madera, y un coco con su pie y guarnición de plata. Esta última pieza - una copa realizada en coco- es un claro ejemplo del uso a la vez funcional y ornamental de esta obra americana que, por su rareza, era apreciada en la Península. En relación a la calavera en lienzo, si esta pintura correspondía a una vanitas y había sido pintada en Quito, constituiría uno de los pocos ejemplos documentados de este género en el Quito de la segunda mitad del siglo XVII. 
se hicieran un cáliz, patena, vinajeras, salvilla y campanilla, y una vez realizadas se mandasen a la iglesia del Santo Cristo de los Remedios de Moguer (Huelva) ${ }^{15}$. Asimismo, donaba 100 pesos para que se hiciera un vestido a la imagen de Nuestra Señora de Montemayor de Moguer, destinando lo que sobrase al adorno de dicha imagen ${ }^{16}$. Por su parte, Francisco Rubín de Celis, natural de Rábago (Cantabria) y también residente en Quito, mandaba en su testamento, redactado en agosto de 1683 , varias piezas de platería a su pueblo ${ }^{17}$. Para la iglesia de Santa María de Bielva (Herrerías, Cantabria), donde había sido bautizado, destinaba varias piezas de plata $^{18}$. El donante era en este caso muy preciso en sus deseos, pues indicaba expresamente que una lámpara se pusiera delante del Santísimo Sacramento, mientras que la otra, de menor tamaño, se colocaría ante la imagen de Nuestra Señora del Rosario, patrona del lugar. Los dos ciriales y blandones habrían de ir destinados al altar mayor ${ }^{19}$. El testador pedía el mayor cuidado y diligencia en la remisión de las piezas hasta su destino, que recibirían los mayordomos del Santísimo y de la Virgen. Para costear el envío de estas piezas destinaba 550 patacones ${ }^{20}$.

Distinto a los anteriores era el motivo por el que en 1691 se mandaba a Europa el retrato de Mariana de Jesús. Era la causa de beatificación la que propició que se desplazase a España el capitán Juan Guerrero de Salazar, sobrino de la religiosa. Junto con el retrato de su tía, llevaba los poderes de la ciudad de Quito, las informaciones jurídicas y gran cantidad de limosnas ${ }^{21}$. El capitán se había embarcado en la Armada de Diego de Córdova, Marqués del Bado del Maestre, en el galeón llamado "el Ángel”. Durante la travesía tuvo un sueño en el que su tía le decía que sacase el retrato de la caja en que estaba guardado. Este cuadro se colocó en la capilla "con notables aprecios de su original". Tras naufragar el bajel “Ángel” a causa de una tormenta, pudo salvarse Guerrero de Salazar junto con el retrato, en una barca improvisada, hasta alcanzar otro de los navíos.

${ }^{15}$ ANH, Sección Protocolos Notariales, 6 a Notaría, Vol. 82, fol. 381 r.

${ }^{16}$ Parece ser que este vestido sí se haría directamente en España, aunque no queda del todo claro.

${ }^{17}$ ANH, Sección Protocolos Notariales, $1^{\text {a }}$ Notaría, Vol. 246, fol. 83 r y ss.

${ }^{18}$ Éstas eran dos lámparas, cuatro blandones, cáliz y patena consagrados, salvilla, vinajeras, campanilla "todo dorado el Insensario", la naveta y una cuchara.

${ }^{19}$ Es decir, que pretendía que sus donaciones fueran bien visibles por los feligreses del lugar, ya que destacarían en los espacios más importantes de la iglesia de Herrerías.

${ }^{20}$ Como sucedía con la lámpara remitida al convento de Pasión de Sevilla, se destinaban ciertas cantidades de dinero para el aceite de las lámparas, que habrían de alumbrar perpetuamente.

${ }^{21}$ MORÁN DE BUTRÓN, Jacinto: La azucena de Quito que broto el florido campo de la Iglesia en las Indicas Occidentales de los Reynos del Perù, y cultivò con los esmeros de su enseñança la Compañia de Jesus, la V. Virgen Mariana de Jesus Paredes y Flores... Imprenta de don Gabriel del Barrio, Madrid, 1724, p. 413. 
Otra justificación tenía el primer envío de loza quiteña al presidente de la Contratación de Cádiz. Lo citamos aquí porque explicita otras razones tras la remisión de piezas quiteñas. En el envío efectuado en 1773, se trataba de que Carlos III auxiliase la obra emprendida en la Fábrica de Quito. Para ello se preparó una remesa en la que predominaban los útiles de mesa, mientras que constituía una excepción el "perrito sobre su peñasco color celeste con oro", único exponente de pieza decorativa producida en la fábrica ${ }^{22}$. Mucho mayor fue el segundo envío, destinado al rey, que constaba de 22 cajones repletos de piezas decorativas de tema religioso, mitológico, retrato, frutas, animales, figuras de temática costumbrista y también útiles de mesa.

\section{LA PREPARACIÓN DEL ENVÍO: LA DISTRIBUCIÓN DE LAS PIEZAS Y LOS CUSTODIOS}

Aunque no siempre se cuenta con información específica sobre la disposición de los bienes enviados a la Península, afortunadamente encontramos documentos que sí detallaban no sólo cómo se distribuirían las piezas, sino también quiénes eran los encargados de llevar a buen puerto el traslado. Las personas a cargo de custodiar el envío, las depositarias de obras de arte y sumas de dinero con destino a la Península, solían ser gente cercana al personaje, que contaba con su total confianza. Por ejemplo, en el caso del obispo De la Peña Montenegro, era su sobrino, Francisco de Samamed y Montaos, quien se hacía cargo del envío en $1662^{23}$. Pero el hecho de delegar en persona de confianza no era garantía para que el envío llegase a su destino en tiempo y forma.

En relación a la disposición de los géneros enviados a la Península, contamos con algunos interesantes testimonios documentales. Podríamos traer a colación, entre otras, las remesas del obispo Ladrón de Guevara y del capitán Bartolomé Zuleta de Reales. En julio de 1708, Diego Ladrón de Guevara daba en la localidad de Tumbaco un poder a Mateo de la Escalera y Velasco, quien antes había actuado como su apoderado, para que se encargase de remitir a España varias cantidades de dinero y algunas alhajas ${ }^{24}$. En un documento que resulta de mucho interés por la gran cantidad de datos que proporciona, se señala la necesidad de protección del envío durante todo el viaje, obligando a que las cantidades de pesos en oro se ensayasen en Lima "por el contraste de estos Reinos". Se especificaba que la protección debería ser tanto en el Mar del Sur como del Norte. Además,

${ }^{22}$ PANIAGUA PÉREZ, Jesús: "Un intento de reactivación económica en el Quito del siglo XVIII...”, op. cit., pp. 101-102. En España se había acusado recibo de este envío en 1774.

${ }^{23}$ JUSTO ESTEBARANZ, Ángel: “Don Alonso de la Peña Montenegro...”, op. cit., p. 642 .

${ }^{24}$ Sección Nobleza del Archivo Histórico Nacional, ALMODOVAR, C.53, D.8. 
aparecen detalladas las marcas de los cajones que contenían las piezas. Éstas son $M B$ y $M E$. $M B$ correspondería a las cajas y baúles en que irían el oro y su ropa. Serían la número 1 y la número 2. La plata iría en los cajones 35 y 36 de la marca $M E$, y la colgadura de cumbes en el cajón 37 de esa marca. Se señalaba que de todas las cantidades referidas en el envío habría que rebajar los costes que se hubieran causado. José de Munive había recibido el dinero y las alhajas del obispo, que se detallaban en inventario incluido en este documento. Las alhajas aparecen descritas detalladamente, especificándose el peso de cada una de las piezas, en vez de su valor económico ${ }^{25}$. Quizás una de las más llamativas fuera el pectoral de Santo Toribio de Mogrovejo, que pesaba 39 castellanos y un tomín ${ }^{26}$. La entrega del oro en España se había de hacer a Diego de Morales y Velasco, y en su falta Manuel de Gamboa, y en su falta Lorenzo Matheu y Villamayor, todos ellos caballeros de la Orden de Santiago. Para los gastos de conducción de las cantidades que donaba el obispo había destinado un montante de 1.360 pesos. José de Munive habría de recibir 500 pesos por la custodia de las piezas, pero en el momento de redactarse el documento aún no los tenía en su poder. A esta carta acompañaba una memoria, firmada por el propio Munive en Lima el 29 de Diciembre de 1720, en la que se detallaban los bienes del obispo embarcados en el navío el Águila para "los Reynos del Puerto de esta Ciudad"27. El dinero enviado -40.000 pesos en doblones- se había guardado en cuatro baúles de la cama y dos petacas de los pontificales, y otras cantidades en 39 taleguitas. De las piezas de oro y plata inventariadas se especifica su peso, pero no su valor económico. Otras remesas del obispo, en años posteriores, fueron a cargo de otras personas, entre ellas Nicolás Navarro, mercader flotista, quien debía entregarlas en El Puerto y en Cádiz a varias personas ${ }^{28}$. De entre todas las piezas que mandó, destacaban sendas reliquias de los santos americanos

${ }^{25}$ La misma información aparece en el documento de 1706 en el que Francisco Cipriano de Mena da cuenta de los objetos y cantidades que ha recibido del obispo para trasladarlos a España. Véase Sección Nobleza del Archivo Histórico Nacional, ALMODOVAR,C.53,D.7. Éste, llegado a Cartagena de Indias, negociaría con los Diputados del Comercio de Sevilla que estaban en la ciudad para que éstos se hicieran cargo de la conducción de los cajones, no pudiendo éstos cargar otros costos en la conducción que los previamente pactados. En caso de que los diputados se negasen a aceptar las condiciones, se entregaría la carga a los maestres de plata de las naves Capitana y Almiranta de la armada de galeones que estaba en Cartagena, para que éstos la llevaran a Sevilla. En el documento incluso se especifica la división de la carga en las dos naves.

${ }^{26}$ También mandaba el prelado a la Península un Santo Cristo de oro con su "cabrestillo", que pesaba 34 castellanos, y varios cálices, patenas, tembladeras, salvillas, una pileta de agua bendita, cajetas, jarros, entre otras piezas diversas.

${ }^{27}$ Sección Nobleza del Archivo Histórico Nacional, GUEVARA,C.4,D.80. La información del navío aparece en Sección Nobleza del Archivo Histórico Nacional, GUEVARA,C.4,D.79. Esta carta está firmada en marzo de 1721.

${ }^{28}$ Sección Nobleza del Archivo Histórico Nacional, GUEVARA,C.4,D.84, fol. $11 \mathrm{r}$. 
Toribio de Mogrovejo y Rosa de Lima29. A diferencia de otras mandadas a la Península, el prelado puso un gran interés en que ambas se conservasen dentro de la familia, y no se vendiesen.

Otra remesa sobre cuya preparación tenemos noticias es la de la lámpara de plata que en 1696 donaba el capitán Bartolomé Zuleta de Reales al convento de monjas de Pasión de Sevilla. Ésta se había entregado a Juan Espinosa de los Monteros, natural de Loja y residente en Quito ${ }^{30}$. Debido a su gran tamaño, la lámpara se mandaba desmontada y guardada en dos cajones de madera forrada en piel de vaca, que se hallaban precintados y numerados con los números uno y dos, más una marca a fuego - para la que se había dejado un hueco en el documento, pero que no se rellenó, y que por lo tanto desconocemos- ${ }^{31}$. El paradero actual de la lámpara no se conoce, pues no quedan noticias del mismo ${ }^{32}$.

\section{LA ARDUA TRAVESÍA (RUTAS, MEDIOS DE TRANSPORTE Y DIFICULTADES)}

El trayecto desde Quito hasta Tierra Firme, con destino a la Península, se podía hacer de dos formas, según detalla Guerra ${ }^{33}$. El preferido era mixto, con tramos

29 "Un esclavonsito de fierro de la cadena q[ue] le tenia Santa Rosa de Lima y assí por la Reliquia como por memoria de su Dueño la Reservare Convenia de V md y los demas sres". Véase Sección Nobleza del Archivo Histórico Nacional, GUEVARA,C.4,D.84, fol. $12 \mathrm{r}$.

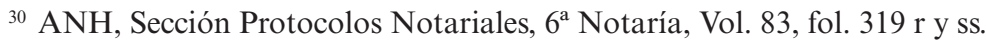

${ }^{31}$ La distribución en los cajones se hizo de la siguiente manera: en el número 1 se habían guardado el pie de la lámpara con seis cartelas "puestas", el remate con dos piezas, una vara con su tornillo abajo y arriba y una argolla, y "otra piesa que son quatro las de la dha bara", una pieza donde se pone la lámpara de vidrio con tres piezas soldadas, seis piezas sueltas de los seis vasos en donde se ponen las lamparillas, y seis cartelas grandes y seis pequeñas todas con sus tornillos. Por su parte, el cajón número 2 contenía la perilla de la lámpara, la caja de las seis lamparillas, dos platones grandes que pesaban 19 marcos, 3 onzas y media, una palangana de 4 marcos y media onza, cuatro candeleros que pesaban 11 marcos, 6 onzas y una cuarta, la lámpara grande de dos piezas, las cadenas de ocho eslabones, una pilita de agua bendita que pesaba 9 onzas, una imagen de la Candelaria de plata y un tornillo de una cartela grande de la lámpara. ANH, Sección Protocolos Notariales, $6^{\mathrm{a}}$ Notaría, Vol. 83, fol. 319 v. De esta manera quedaban perfectamente dispuestas todas las piezas, y así habrían de llegar a su destino sevillano.

${ }^{32}$ Fraga Iribarne supuso que algunos retablos, esculturas y objetos de culto de la iglesia de Pasión se los pudieron llevar las religiosas de Madre de Dios, o bien quedar en la iglesia, abierta todavía unas décadas después de la extinción del convento. Véase FRAGA IRIBARNE, María Luisa: Conventos femeninos desaparecidos. Arquitectura religiosa perdida durante el siglo XIX en Sevilla. Ediciones Guadalquivir, Sevilla, 1993, p. 132.

${ }^{33}$ GUERRA, Manuel Patricio: "Una pintura, un memorial, una historia...", op. cit., p. 349. 
por tierra y otros por $\operatorname{mar}^{34}$. La otra opción era por vía terrestre ${ }^{35}$. A partir de ahí, se procedía a embarcarse con destino a la Península. Lógicamente, la travesía por mar desde tierras americanas hasta la Metrópolis era ardua, y en no pocas ocasiones se perdieron valiosos envíos, de los que se tiene referencia documental merced a la correspondencia entre las autoridades americanas y peninsulares. Para el caso quiteño, en la época que estamos estudiando existen testimonios tanto de envíos exitosos - entre ellos los que hicieron los prelados De la Peña Montenegro y Ladrón de Guevara - como de otros que se vieron truncados por diferentes motivos. En el caso de la donación que hacía Zuleta de Reales, Juan Espinosa de los Monteros recibió la carga en Quito y se comprometía a llevarla a Cartagena de Indias, donde la entregaría a José Antonio Zuleta de Reales y Córdoba, sobrino del capitán, y en su ausencia a Francisco de Córdoba, capitán del patache de la Margarita, y en su ausencia al capitán Juan de Córdoba ${ }^{36}$. Todos estos personajes eran sevillanos, que en ese momento estaban en tierras americanas ${ }^{37}$. Al llegar a Sevilla entregarían los cajones a Clemencia y Brígida Zuleta de Reales, hermanas del capitán y profesas en el convento de la Pasión.

Pero no siempre tuvieron éxito los envíos de cajones cargados de obras y destinados a la Península. Hubo ocasiones en que no llegaban a su lugar de destino. El problema se podía producir de diferentes maneras, y en dos momentos: sufriendo algún tipo de percance en propio suelo americano, o algún ataque o accidente por mar, desde Tierra Firme hasta España. De las dos tipologías tenemos noticias procedentes de Quito, y además del mismo personaje, que detallamos a continuación. Se trata del Dr. Joseph Fausto de la Cueva, deán de la catedral de Quito, comisario del Santo Oficio y catedrático de prima jubilado en Sagrados Cánones en la Universidad de Santo Tomás. Natural de Loja e hijo de un matrimonio ursaonense, había testado en junio de 1715. A su sobrina, Luisa de Cevallos y de la Cueva, residente en Madrid, le enviaba un cajoncito cerrado con "cajeticas de oro", cabestrillos y doblones, por un importe de unos 2.000 pesos $^{38}$. El cajoncito se lo había entregado a Cristóbal Jijón, que en Panamá debía dejarlo a alguien de su confianza, quien finalmente lo haría llegar a la sobrina. En caso de no encontrarla -o de hallarse ésta muerta-, las piezas no se entregarían a otra persona, sino que se venderían en Madrid y se mandaría lo obtenido en forma de ropa y alhajas. El cajoncito con las alhajas iba en un navío que se quemó saliendo

${ }^{34}$ Quito, Latacunga, Ambato, Riobamba, Chimbo, Puerto Quilca, Bodegas, Guayaquil, Esmeraldas por vía marítima, Tumaco, Buenaventura y Tierra Firme.

${ }^{35}$ De Quito a Cartagena y Portobelo pasando por Ibarra, Pasto, Cali, Buga, Cartago, Mariquita, Honda, y vía curso del río Magdalena hasta Vare, Mompox, Cartagena y Portobelo.

${ }^{36}$ ANH, Sección Protocolos Notariales, $6^{\text {a }}$ Notaría, Vol. 83, fol. 319 v.

${ }^{37}$ ANH, Sección Protocolos Notariales, $6^{\mathrm{a}}$ Notaría, Vol. 83, fol. $322 \mathrm{v}$.

${ }_{38}$ ANH, Fondo Especial, Caja 9, Vol. 23, Documento 723, fol. 30 r. 
de Portobelo. Por lo que relata el testador, dicho cajoncito se abrió y se halló "buena parte de doblones menos, y otras alajitas de oro"39. Por lo tanto, fue durante el comienzo de la travesía marítima cuando se perdieron parte de las piezas. El segundo caso lo constituye otro envío de platería, también para su infortunada sobrina, esta vez vía Cartagena de Indias, truncado por estar la ciudad invadida por el francés ${ }^{40}$. Pero el deán desconfiaba de Diego de Unda, persona a quien se le había hecho el encargo del traslado de las piezas. Parece ser que se había escamoteado el dinero, "según comun voz y fama publica" entre los habitantes de esa provincia en la ciudad de Cartagena. Habiendo fallecido Diego de Unda en Popayán, se hizo testamento, sin que Sebastián de Torijano, encargado de elaborar el documento, reconociese la deuda que todavía tenía con Joseph Fausto de la Cueva. Eso sí, el sacerdote advertía del grave perjuicio que la conducta de Torijano tendría para con su alma y la del ya finado Unda ${ }^{41}$. Además, se disponía a demandarlo hasta cobrar lo que se le debía.

En conclusión, los casos analizados en este artículo dan testimonio del proceloso viaje de las remesas de obra quiteña a España durante el barroco. En primer lugar, muestran los variados motivos por los que se podían enviar desde Quito obras a la Península, y también la diferente importancia artística y pecuniaria de cada uno de ellos, en función de la calidad del personaje que donaba las obras y de la situación económica que gozaba. Los custodios del envío, la distribución de las piezas en cajas y fardos, marcados convenientemente para su efectiva identificación y manejo, el coste que el proceso llevaba aparejado y las dificultades que se encontraban a lo largo del viaje son datos que, gracias a la huella documental conservada en los archivos nacionales y extranjeros, se pueden rastrear en la actualidad, y que contribuyen a enriquecer el conocimiento de la circulación de obra de arte desde Quito a España.

Fecha de recepción: 30 de septiembre de 2014

Fecha de aceptación: 28 de noviembre de 2014

${ }^{39}$ El testador mandaba cobrar lo que procediese "para que descargue su consiensia" (de Cristóbal Jijón y de Gabriel de Escorza), "si no ubieren persevido los fardos como diçe, y llebadoselos enemigos Piratas". Véase ANH, Fondo Especial, Caja 9, Vol. 23, Documento 723 , fol. $30 \mathrm{r}-\mathrm{v}$.

${ }^{40}$ El monto era elevado. En total, la intención del sacerdote lojano era la de enviar más de 7.000 pesos, y en doblones, cabestrillos y cajetas de oro, "más de dos mil y quinientos pesos que importaron". Véase ANH, Fondo Especial, Caja 9, Vol. 23, Documento 723, fol. $30 \mathrm{v}$.

${ }^{41}$ ANH, Fondo Especial, Caja 9, Vol. 23, Documento 723, fol. 31 r. 